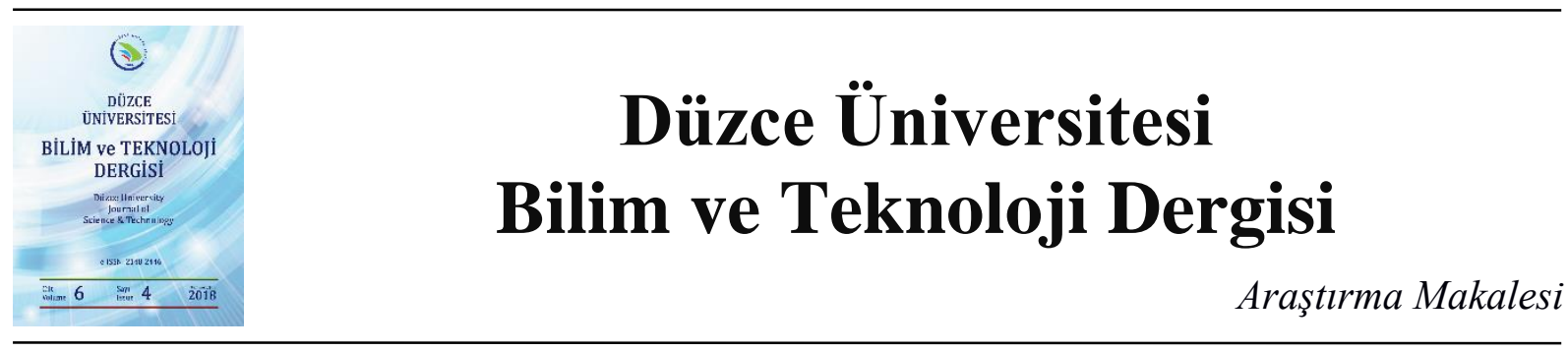

\section{Nesnelerin İnterneti Teknolojileri ile Gerçek Zamanlı Okul Servisi ve Öğrenci Takip Sistemi Tasarımı}

\author{
Buse ÇELIK ${ }^{a}$, Kerem KÜÇÜK ${ }^{a, *}$, Cüneyt BAYILMIŞ ${ }^{b}$ \\ ${ }^{a}$ Bilgisayar Mühendisliği Bölümü, Mühendislik Fakültesi, Kocaeli Üniversitesi, Kocaeli, TÜRKiYE \\ ${ }^{b}$ Bilgisayar Müh. Bölümü, Bilgisayar ve Bilişim Bilimleri Fakültesi, Sakarya Üniversitesi, Sakarya, TÜRKIYYE \\ * Sorumlu yazarin e-posta adresi: kkucuk@kocaeli.edu.tr
}

\begin{abstract}
ÖZET
Nesnelerin İnterneti tabanlı çözümler sağladığı kolaylıklar ve maliyetlerinin etkin olması nedeni ile gün geçtikçe artan kullanıma sahip olmaya başlamıştır. Özellikle son yıllarda gelişmeye başlayan akıllı şehir kavramı ile birlikte hemen hemen her alanda var olmaya başlayan bu teknolojiler yüksek hızda veri iletişimini destekleyebilmektedirler. Bu çalışmanın amacı servis araçlarının ve öğrencilerin hareketlerinin gerçek zamanlı olarak izlenmesidir. Böylelikle araca biniş ile okula varıncaya kadar geçen süre içerisinde tüm grupların bilgilendirilmesi ve öğrencilerin güvenli bir biçimde okula ulaştırılması sağlanmaktadır. Bu çalışma ile el ile yapılmakta olan tüm işlemler sistematik bir hale getirilmektedir. Bu amaç ile HM-11 Bluetooth düşük enerji modülü işaretçi cihazları, gerçek zamanlı olarak çalışabilen bir veri tabanı olan Firebase bulut platformunu, işaretçi cihazlara erişimi sağlayabilen MIT App Inventor Android mobil uygulamasını ve web uygulamasını kullanan okul servisi ve öğrenci takip sistemi sunulmaktadır.
\end{abstract}

Anahtar Kelimeler: Nesnelerin interneti, Bulut sistemler, Mobil programlama, Bluetooth düşük enerji, Araç takip sistemleri

\section{Real-Time School Bus and Student Follow-Up System Design with Internet of Things Technologies}

\begin{abstract}
Internet of things (IoT) based solutions have a growing use due to their facilities and cost effective properties. Especially, with the concept of smart city, which has started to develop in recent years, almost all the fields are beginning to exist and these technologies can support data communication at high speed. The main purpose of this study is to monitor the service tools and the movements of the students in real time. In this way, all groups are informed during the period between the boarding and the arrival of the school, and students are safely delivered to the school. With this work, all the processes that are being done manually are systematized. The service bus and student follow-up system is presented which is consist of HM-11 Bluetooth low energy module beacon devices, Firebase cloud platform that works as a real-time database, MIT App Inventor Android mobile application that
\end{abstract}


reaches to beacon devices and let the parents follow up their students and web application that manage the system in this paper.

Keywords: Internet of things (IoT), Cloud systems, Mobile programming, Bluetooth low energy, vehicle tracking systems

\section{GiRiș}

$\mathrm{N}^{2}$ esnelerin interneti (Internet of Things, IoT) teknolojisinin kullanımı gün geçtikçe hayatımızda daha fazla yer almaya ve bir çok problemin çözümüne katkı yapmaya başlamıştır [1]. Son beş yılda hayatımızda yerini almaya başlayan, birçok büyük ticari şirketin yatırım yaptığı işaretçi cihazları (Beacon) nesnelerin interneti teknolojisinin en popüler uygulama donanımlarından biridir [2-3]. IoT kavramı ile ilk olarak K. Ashton tarafından tedarik zinciri için hazırladığı sunumda ortaya atılmıştır. Bununla birlikte günümüzün hıla gelişen bilişim teknolojisi ve veri ihtiyacı nedeniyle; düşünülenden daha geniş bir alanda yaklaşık olarak yirmi milyar cihazın bağlı olduğu iletişim ağına dönüşmüştür [4].

Günümüze kadar gelen süreçte algılayıcılar günlük hayattaki yerini alarak birçok uygulamada kullanılmaya başlanmıştır. Sayısı milyarları bulan bu düşük maliyetli algılayıcılar ile birlikte şirketler IoT'ne olan yatırımlarını arttırarak, dijitalleşme yolunda büyük adımlar atmışlardır. Algılayıcıların kapsama alanlarını geliştirip her yerde kullanılabilir hale getirilmesi ile beraber; IoT her cihazın kendine ait bir adresinin bulunduğu cihazların kendileri arasında iletişim kurabildiği, tüm dünyada kabul gören hemen hemen herkesin hayatına kadar giren bir bilgisayar ağı ve bu ağdaki cihazların belirli bir haberleşme protokolü ile çift yönlü haberleşme işlemleri olarak açılanabilmektedir [5].

Son on yıl göz önüne alındığında mobil telefonların kullanımının gün geçtikçe hızla arttığı görülmektedir. Sayısal ve sanal dünyada sosyal içerikli uygulamaları sıklıkla kullanan yeni nesil mobil kullanıcılar için gerçek dünya ile sayısal dünyanın birleştiği bilişim ve bilgi teknolojileri büyük önem arz etmektedir. Bu teknolojiye yönelik çözümler üreten farklı girişimler bulunmaktadır [6]. İşaretçi, Bluetooth düşük enerji (Bluetooth Low Energy, BLE) teknolojisinin popüler kullanım alanlarından bir tanesi konum temelli uygulamalar olarak ortaya çıkmaktadır [7]. Genellikle tek bir Bluetooth vericisinin tek yönlü olarak ortama ilettiği ve yayın yaptığı, hesaplama özelliği olmayan, gönderdiği kendine özgü bilgi paketi ile mobil kullanıcıların cihazlarında kurulu olan uygulamalarıyla etkileşime geçerek, fiziksel çevre ile etkin haberleşme sağlayan işaretçi cihazlar, ilk olarak Apple tarafından piyasaya çıkarılmıştır. Hem Apple'ın mobil işletim sisteminde hem de Android işletim sistemine sahip akı1ll telefonlar ile birlikte kullanılabilmektedirler. Takip eden süreçte çok fazla sayıda işletme kendi çözümleri için kendi işaretçi cihazlarını üretir hale gelmiştir [8]. Bu teknolojinin potansiyel kullanım alanlarından bir tanesi de nesnelerin takibi ve konumlarının tespit edilmesidir. Öğrencilerin okul servisi içerisindeki yoklamaları tipik olarak yardımcı elemanların talimatları doğrultusunda otomatik olmayan bir yol ile yapılmaktadır. Bununla birlikte birçok serviste bu işlem hiç yapılmamakta veya bu işlemi gerçekleştirecek bir yetkili bulunmamaktadır. Bu durum tamamen göz ardı edilse dahi benzer ihmaller sonucu öğrencilerin güvenliklerini tehlikeye düşürecek durumlar oluşabilmektedir. 
Bu çalışmada donanım olarak kullanılan HM-11 Bluetooth düşük enerji işaretçi (Bluetooth Low Energy, BLE) cihazları nesnelerin internetinin bir ürünü olarak kullanılmıştır. Pasif olarak sinyal yayan işaretçi cihazları mesafeye bağlı olarak öğrencilerin servis içinde olup olmadıkları ile ilgili gerçek zamanlı bilgi edinilmesini sağlamaktadır. Bunun için MIT App Inventor uygulaması kullanılarak gerçek zamanlı okul servisi ve öğrenci takip sisteminde bulunan tüm grupların kullanımına uygun mobil uygulama geliştirilerek, Google Firebase bulut ürünü ile ilişkilendirilmiştir. Ayrıca tüm sistemin yönetilmesi, işaretçilerin öğreniciler, servisler ve araç kullanıcıları ile eşleştirilmesini sağlayan Web ara yüzü oluşturulmuştur.

Çalışmanın organizasyonu şu şekilde oluşturulmuştur. Bölüm 2'de ilgili çalışmalar tanıtılmaktadır. Bölüm 3'te Bluetooth düşük enerji çözümü ve oluşturulan BLE işaretçi cihazı tanıtılmaktadır. Bölüm 4'de tasarlanan gerçek zamanlı okul servisi ve öğrenci takip sisteminin yapısı, sinyalizasyon prensibi, mobil ve web yazılım alt yapısı ve kullanımı anlatılmaktadır. Sonuçlar ve değerlendirmeler son bölümde açıklanmaktadır.

\section{II. İLGiLI ÇALIȘMALAR}

Beacon gibi BLE kullanan cihazlarla yapılmış birçok çalışma bulunmaktadır. Bunun en önemli nedenlerinden birisi Bluetooth'un dünyadaki telefonların \%90'ının sahip olduğu bir teknoloji olmasıdır. Kullanıcılar günlük olarak kullanmasa da Bluetooth, nesnelerin interneti için önemlidir. Beacon ekosisteminin de tüm altyapısını oluşturur [9]. Google firması Beacon Eddystone olarak piyasaya sunduğu teknoloji sayesinde BLE işaretçi cihazın kapsama alanı içerisinde mobil cihaz ve uygulama ile etkileşimi sağlamakla birlikte bir web adresini çağırabilme özelliğini de getirerek işaretçi cihaz kullanımı ve üretimi için farklı bir gelişim sunmaktadır. Gerçek zamanlı okul servisi ve öğrenci takip sistemine benzerlik gösteren ve benzer teknolojiler kullanan çalışmalardan bir tanesi işaretçi cihaz takip çalışmasıdır. Kullanıcı mobil uygulamayı açtığında ilk olarak etraftaki Bluetooth cihazlarını tarayıp eşlenmiş olan işaretçi cihazı bulmaktadır. Daha sonra butona bastı̆̆ında işaretçi cihazın gönderdiği sinyallere göre konumunu belirleyip kullanıcıya yakın $\mathrm{m} 1$ uzak $\mathrm{m} 1$ olduğunu bildirmektedir. Gerçekleştirilen bir diğer çalışma ise işaretçi cihaz ile yoklama sistemidir. Öğretmen sınıfa girince yoklamayı açtıktan sonra sınıfta bulunan öğrenciler kendilerini bulup imza atabilmektedirler. Öğrenci sadece bir kez kendi yerine imza atabilmektedir ve işaretçi cihaza en fazla 15m uzaklıkta olmalıdır [7].

Beacon üzerine yapılan çalışmalar dünyada hız kazanırken, ülkemizde de BLESH (Bluetooth Low Energy Smart Hub) ekibi bu konuyla çalışanlardan bir tanesidir. BLESH ürettiği Beacon'ları anlaştığı markalara kurarak, hem IOS ve hem de Android platformlara uyumlu yazılım geliştirme kiti sayesinde markaların ve yazılım geliştiricilerin kullanımına açmaktadır. Böylece birçok problem için farklı konum bazlı olarak çözümler ile farklı gruplara ulaşım imkanı sağlanmaktadır. BLESH cihazları şu an Türkiye'de otuzun üzerinde farklı şehirde üç binden fazla noktada bulunmaktadır [10].

Nesneleri interneti kavramının en yaygın kullanıldığı alanlardan bir tanesi de akıllı ulaşım sistemleri olarak gösterilebilmektedir. Ulaşımın daha akıcı ve güvenilir sağlanması yanında bu araçların ve yayaların takip edilmesi de araştırmalar içerisinde yer bulmuştur. Jisha ve arkadaşları RFID/GPS/GSM/GPRS gibi kablosuz haberleşme sistemlerini kullanan ve birçok hizmet sağlayabilen bir okul servisi izleme sistemi geliştirmişlerdir [11]. Sistem önerilen algoritma ile desteklenerek okul servisinin varış saatini de tahmin edebilmektedir. Bir diğer çalışmada; ebeveynlerin çocuklarını gerçek zamanlı olarak takip etmelerine yardımcı olan SMS tabanlı bir çözüm önerilmiştir [12]. GPS modülünün 
yerini tespit etmek ve çocuğun kimliğini tanımlamak için sistemde yerleşik bir RFID kartı kullanılmaktadır. Dolayısıyla, bir çocuk bir servise bindiğinde, kimlik kartında bulunan RFID etiketi serviste bulunan okuyucu tarafından algılanmaktadır. Böylelikle sistem çocuğu tanımlayarak mevcut konum ve zaman bilgilerini ebeveynlere bir metin mesajı göndermektedir. Bununla birlikte sabah ve öğleden sonraları ebeveynlerin öğrencilerini servisten almak için uzun süre beklemeleri gerekebilmektedir. Özellikle bu konuda artan trafik sıkışıklığı problemi daha da çözülmez hale getirmektedir. Bu sorunu çözmek için önerilen Smart Bus sistemi mobil ve web uygulaması sunmaktadır [13]. Sistem, çocukların varış zamanını tespit etmek için ebeveynler, okul ve servisin sahip olduğu uygulamalar aracılığıyla otomatik ve kolay bir şekilde iletişim kurmasını sağlamaktadır. Servis uygulaması ebeveynlere evlerine birkaç dakika içerisinde ulaşacağı bilgisini vermektedir. Ayrıca, sistem ebeveynlere çocuklarının okulda olmayacağı bilgisini de paylaşmalarını sağlamaktadır. Bu sistemler için geliştirilen bir diğer çözüm ise Smart School Bus uygulamasıdır [14]. Tasarlanan mobil uygulaması, ebeveynler için çocuklarını takip edebilmesini ve okul yönetimini için ise sürücüleri kontrol edebilmesine imkân tanımaktadır. Önerilen sistem, aracın konumu, güzergâhı, hızı, yolcu listesi, sürücülerin takvime uygunluğu ve birçok farklı parametre hakkında gerçek zamanlı bilgi sağlayabilmektedir. Bu sistemde RFID ve GPS teknolojileri ile birlikte ESP8266 mikro denetleyici kullanılarak iki bileşen Wi-Fi üzerinden uzak bir sunucuya bağlanmaktadır. Ülkemizde bu alanda yapılan çalışmalardan bir tanesi de İstanbul Bilişim ve Akıllı Kent Teknolojileri firması tarafından geliştirilen ülkemizde ilk olma özelliğini taşıyan IoT tabanlı bir bulut bilişim altyapısı ile trafik yönetim sistemidir. Geliştirilen sistem özellikle kavşaklarda oluşan uzun kuyrukların azaltılmasını sağlayarak daha konforlu ve ekonomik ulaşım sağlamaktadır. Aynı firma tarafından hizmetimize sunulan trafik yoğunluk haritası uygulaması ile şehirdeki ana yolların trafik yoğunluğu bilgisi, anlık kaza haberleri, gerçek-zamanlı görüntüleme hizmetleri ve anlık hava durumuna bağlı olarak buzlanma gibi bilgilere erişim imkânı sunulmaktadır. Ülkemizde uygulamaya koyulan bir diğer önemli uygulama ise farklı belediyelerin kullandığı anlık belediye otobüsü takip sistemidir. İnternet üzerinden kent içerisinde seyir halinde olan bütün otobüslerin canlı olarak takip hizmeti verilmektedir. Otobüslerin o an nerde olduğu kullandığı güzergâh canlı olarak takip edilmektedir. Bu sayede bir otobüsün bir noktaya ne zaman geleceğini öğrenmek için duraktaki ekranlardan takip etme zorunluluğu ortadan kalkmıştır [16].

Tüm bu çalışmalar ile birlikte, sunulan çalışma genel sistem mimarisi anlamında ebeveyn mobil uygulaması, sürücü mobil uygulaması, işaretçi cihaz ve web uygulaması içermesi nedeni ile önerilmiş olan diğer çözümlere göre ek donanım gereksinimi çok düşük seviyededir. Bununla birlikte öğrencilerin mobil telefon bulundurmalarına ihtiyaç bulunmamaktadır. Ayrıca öğrencilerin servise binişlerinde herhangi bir kart okuyucu ile iletişime geçme zorunluluğu da ortadan kaldırılmaktadır. Bununla birlikte gerek ebeveynin öğrencisini gerek de okul yönetiminin serviste bulunan öğrencilerin listesini görebilmesi sistemin diğer bir avantajı olarak görülmektedir. Son olarak serviste herhangi bir öğrencinin bulunup bulunmadığının tespiti herhangi bir insan etkileşim ihtiyacına izin vermeksizin yapılabilmesine imkân tanımaktadır.

\section{BLUETOOTH DÜȘÜK ENERJisi TEMELLİ İȘARETÇi VE ÖZELLIKLERİ}

\section{A. IŞARETI CHAZ TEKNOLOJISI: BLUETOOTH DÜŞÜK ENERJI}

Bluetooth düşük enerji, bir dizi aygıta gömülecek şekilde tasarlanan ve bu cihazların uygulamalarını görüntüleyebilen düşük güce sahip bir kablosuz teknolojidir. Uzun çalışma sürelerini desteklerken, 
cihazları düşük güç tüketmeleri için aktif hale getirmesi nedeniyle güç dostu bur teknoloji olarak göz önüne alınmaktadır. BLE ile en dikkat çekici özelliği, herhangi bir zorluk çekmeden akıllı telefonlara ve tabletlere kurulmuş olan uygulamalarda çalışma kabiliyetidir. Bu yetenek, geliştiricilere hâlihazırda piyasada bulunan milyarlarca cihaz üzerinde teknolojiyi mümkün kılmak için uygun bir çözüm sağlamaktadır. Bluetooth Special Interest Group tarafindan tasarlanan ve kullanıma sunulan bir teknolojidir [16]. Sağlık, ulaşım, eğitim, güvenlik ve daha pek çok alanda kullanılabilen BLE, klasik Bluetooth teknolojisinin bir alt grubudur. Bluetooth 4.0'ın temel özelliklerini taşımakla beraber; bağlantı kurulumu olmadan birden fazla cihazdan veri alabilir ve yayın yapabilmektedir. Tablo 1'de BLE ve diğer kısa mesafeli kablosuz iletişim teknolojilerinin veri hızı, sistem frekansı, iletişim mesafesi ve ortalama ağ ömrü özelliklerinin karşılaştırmalı bir özeti sunulmaktadır. Bluetooth düşük enerji teknolojisi diğer kısa mesafeli kablosuz iletişim tekniklerine göre kayda değer miktarda düşük güç tüketimine sahip olduğu görülmektedir.

Tablo 1. Nesnelerin interneti teknolojilerinde kullanılan kablosuz haberleşme teknolojilerinin karşılaştırılması.

\begin{tabular}{c|c|c|c|c}
\hline $\begin{array}{c}\text { Kablosuz iletişim } \\
\text { teknolojisi }\end{array}$ & Veri hızı & Sistem frekansı & $\begin{array}{c}\text { İletişim } \\
\text { mesafesi }\end{array}$ & $\begin{array}{c}\text { Ortalama } \\
\text { Ăg ömrü }\end{array}$ \\
\hline BLE IEEE802.15.1 (v4) & $1 \mathrm{Mbit} / \mathrm{s}$ & $2.4 \mathrm{GHz}$ & $1-50 \mathrm{~m}$ & $1-2$ y1l \\
\hline Bluetooth IEEE802.15.1 & $1-24 \mathrm{Mbit} / \mathrm{s}$ & $2.4 \mathrm{GHz}$ & $10-100 \mathrm{~m}$ & Gün - ay \\
\hline UWB IEEE802.15.3a & $110-480 \mathrm{Mbit} / \mathrm{s}$ & $3.1-10.6 \mathrm{GHz}$ & $10 \mathrm{~m}$ & $1-2 \mathrm{y} 1$ \\
\hline ZigBee IEEE802.15.4 & $20-250 \mathrm{Kbit} / \mathrm{s}$ & $2.4 \mathrm{GHz}$ & $100 \mathrm{~m}$ & 6 ay-1 y1l \\
\hline Z-Wave & $40 \mathrm{Kbit} / \mathrm{s}$ & $868 / 908 \mathrm{MHz} 2.4 \mathrm{GHz}$ & $100 \mathrm{~m}$ & 1 y1l \\
\hline RFID & $4 \mathrm{Mbit} / \mathrm{s}$ & $860 / 960 \mathrm{MHz}$ & $3-100 \mathrm{~m}$ & $5-7 \mathrm{y} 1 \mathrm{l}$ \\
\hline NFC & $424 \mathrm{Kbit} / \mathrm{s}$ & $125 \mathrm{KHz}-960 \mathrm{MHz}$ & $10 \mathrm{~cm}-100 \mathrm{~m}$ & $5-7 \mathrm{y} 1 \mathrm{l}$ \\
\hline
\end{tabular}

\section{B. BEACON}

İşaretçi cihazlar (Beacon), Bluetooth düşük enerji teknolojisini kullanan düşük maliyetli, kablosuz iletişim sağlayan, yakınlığa dayalı pasif sinyal yayan cihazlardır. Bununla birlikte mesafeye bağlı olarak çevrelerindeki akıllı telefonlarla iletişime geçen bu cihazlar, iletişime geçtiği kişilere istenilen mesajların iletilmesini sağlayabilmektedir [16]. İşaretçi cihazlar 50-70 metreye kadar cihazlarla iletişime geçebilmektedirler. Bankacılık, alışveriş, eğitim ve diğer birçok alanda rekabetin artmasıyla beraber 2014'ten bu yana işaretçi cihazlarının kullanımı yaygınlaşmaya başlamıştır ve şirketler bu düşük enerjiyle çalışan cihaza olan yatırımlarını arttırmışlardır. İşaretçi cihazlar aynı zamanda küresel konumlama sisteminin yetersiz olduğu alanlarda sinyal vermeye devam edebilmektedirler. İşaretçi cihazlardan yayılan Bluetooth sinyalleri üzerlerinde dört farklı veri taşımaktadırlar. Bunlar; UUID (Universal Unique Identifier), majör (üst ağ adresi), minör (alt ă̆ adresi) ve sinyal gücü verileridir. UUID tüm ağı tanımlamak için kullanılır ve on altı bayt uzunluğundadır. Üst ve alt ağ adresleri iki bayt uzunluğundadır. İşaretçi cihaz geliştiren birçok firma mevcuttur. Bunlardan bazıları Apple'ın geliştirdiği iBeacon, Google'ın geliştirdiği Beacon Eddystone cihazlarıdır. Bu cihazlar siteme özel pillerle çalışırlar ve pil ömürleri 2-3 yıla kadar çıkabilmektedir.

Şekil 1'de gerçek zamanlı okul Servisi ve öğrenci takip sistemi için kullanılan Texas Instruments firmasının CC2541 çipini içinde barındıran HM-11 BLE işaretçi cihazı görülmektedir. Bluetooth 4.0 standardını desteklemesi nedeniyle düşük güç tüketimine sahiptir. AT komutları kullanılarak farklı özelliklerinin kullanılması veya kapatılması sağlanarak enerji tüketimim farklılaştırılabilmektedir. 2.4 $\mathrm{GHz}$ çalışma frekansına sahip modülün seksenin üzerinde alt çalışma frekansı bulunmaktadır. TI 
CC2541 entegresi iletim işleminde en yüksek $18.6 \mathrm{~mA}$, alımda en yüksek $18.3 \mathrm{~mA}$, uyku modunda ise $1 \mu \mathrm{A}$ tüketimlerine sahiptir. Gerçekleştirilen işaretçi cihaz iletim ve uyku modlarında çalışmaktadır. $\mathrm{Bu}$ modlarda tüketilen güç $3 \mathrm{~V}^{\prime}$ luk besleme gerilimi kullanıldığ durumda iletim modunda yaklaşık olarak $72 \mathrm{~mJ} / \mathrm{s}$, uyku modunda ise $0.0027 \mathrm{~mJ} / \mathrm{s}$ seviyelerindedir. HM-11 modülü delikli kart ile oluşturulmuş basit bir güç kontrol kartı ve 9V'luk pil beslemesiyle öğrencilerin çantasının içerisine yerleştirilebilecek biçimde gerçekleştirilmiştir. Şekil 2'de tasarlanan işaretçi cihaz gösterilmektedir.

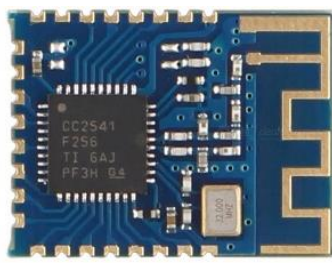

Şekil 1. BLE 4.0 desteği sunan ve sistemde kullanılan İsaretçi modülü (HM-11).

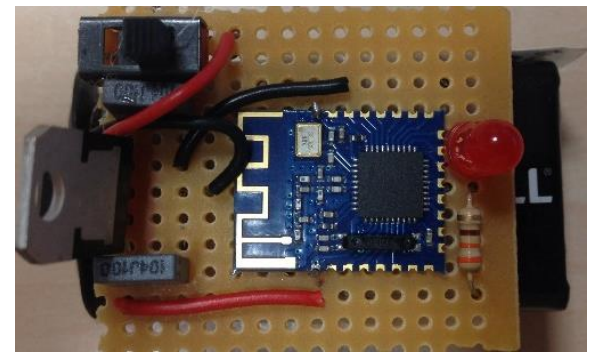

Şekil 2. Tasarlanan güç kartı ve HM-11 ile oluşturularak sistemde kullanılan işaretçi cihaz.

Tasarlanan işaretçi cihaz mümkün olan varsayılanda 625 ms olan Beacon sinyal aralığı enerji tüketimini azaltmak adına yaklaşık olarak 5 sn olarak programlanmıştır. Bununla birlikte servis aracının içini kapsama alanı olarak garanti etmek için radyo gücü $-23 \mathrm{dBm}$ olarak ayarlanmıştır. Böylelikle öğrencilerin servis içerisinde olduğunda Beacon sinyallerinin alıcı tarafından algılanması sağlanmıştır. Gerçekleştirilen işaretçi modülün mevcut parametreler ile işaretçi sinyalini yaymasının yaklaşık olarak 2 yıl boyunca devam edeceği hesaplanmıştır.

\section{GerçeK ZamanLi OKUL SERvisi ve ÖĞRenCi TAKiP Sistemi}

\section{A. SISTEM MIMARISI}

Şekil 3'te gerçek zamanlı okul servisi ve öğrenci takip sisteminin mimarisi ve sistem bileşenleri gösterilmektedir. Gerçek zamanlı okul servisi ve öğrenci takip sistemi; (i) Öğrencilerin yanlarında bulundurdukları, BLE teknolojisini kullanan işaretçi cihazları. (ii) İşaretçi cihazlarıyla etkileşime geçen, servis görevlilerinin kullandığı ve öğrencilerin ebeveynlerinin kullandığı MIT App Inventor tabanlı mobil uygulama. (iii) Gerçek zamanlı bir veri tabanı sistemi olan Firebase. (iv) Yönetim ve idare amaçlı kullanılan Web uygulaması olmak üzere dört temel bileşenden oluşur. Öğrenci okul servisine yaklaştığı anda (servis görevlisinin Bluetooth sinyal alanına girdiği anda) üzerinde bulunan Beacon işaretçi ile servis görevlisinin mobil cihazı Bluetooth paketleri sayesinde etkileşime geçer. Burada önemli olan 
nokta servis görevlisinin Bluetooth cihazının o anda açı olması ve mobil uygulamanın tetiklenerek çalışmasını sağlamasıdır.

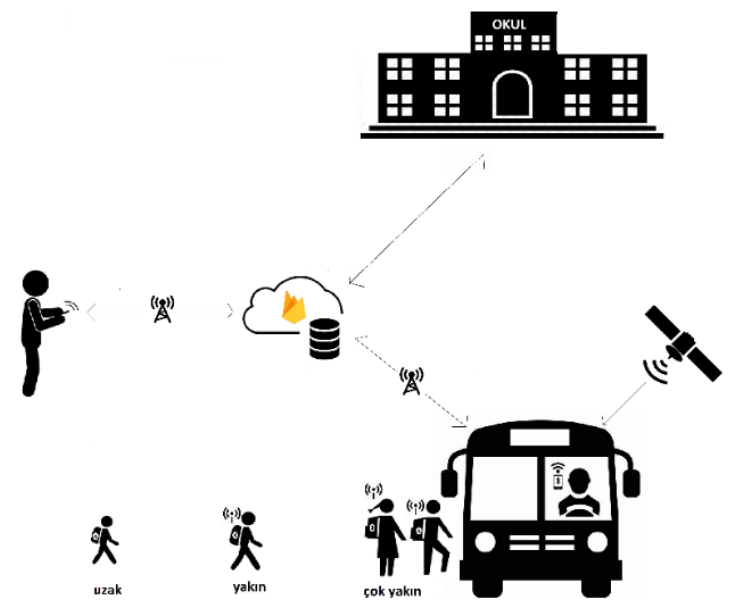

Şekil 3. Gerçek zamanlı okul servisi ve öğrenci takip sistemi mimarisi.

Bununla birlikte, Şekil 4'te gerçek zamanlı okul servisi ve öğrenci takip sistemi için işaretçi, servis şoförlerinin kullandığı mobil uygulama, bulut tabanlı gerçek zamanlı Firebase veri tabanı, velilerin kullandığ1 uygulama bileşenlerinin sinyalizasyon süreci gösterilmektedir. Sinyalizasyon süreci farkl1 durumları içerisinde barındırmaktadır. Tüm bu durumlar Tablo 2'de verilmektedir. Servis sürücülerinin Bluetooth sinyal alanına giren ve veri tabanındaki bilgilere göre eşleşen öğrencilerin sahip oldukları işaretçi cihazlar, öğrencilerin servis içerisindeki durumları hakkında servis sürücülerine ve ebeveynlere bilgi verir. Servis sürücüleri servis içerisindeki öğrencileri listeleyebilir ve bu sayede öğrencilerin unutulma risklerinin de önüne geçmiş olur. Bu aynı zamanda servis sürücüsü içinde servis içi yoklama işlemini gerçekleştirir. Öğrencilerin çantalarında bulunan işaretçi cihazların yaydığı Bluetooth sinyalleri ve bu yayılan sinyallerin barındırdığı öğrenciyi tanımlayabilen ve belirli bir ağ ile eşleştirebilen UUID bilgisine göre servis sürücüsünün kullandığı mobil uygulama ile öğrencilerin taşıdığı işaretçi cihazlar kolaylıkla tanınabilmektedir. Böylelikle her öğrencinin kendine özgü tanımlayıcı bilgisi ile mobil uygulamanın kullandığı veri tabanı eşleştirmesi sonucunda öğrencilerin tanınması gerçekleştirilmektedir. Öğrenciler algılandıkları saat ve tarih ile birlikte bulut veri tabanına araç sürücüsünün mobil cihazının iletişim kanallarını kullanarak kayıt edilirler. Bu işlem gerçekleşirken uygulama belirli aralıklarla servisin konum bilgisini veri tabanına göndermektedir. Tüm bu işlemler gerçek zamanlı olarak gerçekleşmektedir. Sisteme kayıt olmuş olan ebeveynler kullandıkları uygulama sayesinde veri tabanına istek gönderebilmektedirler. Bu giriş isteğinin doğrulanmasından sonra öğrencilerinin servis içerisindeki bilgileri kolaylıkla görüntülenebilmektedir.

Tablo 2. Sistemin çalışması birlikte sinyalizasyon sürecinde meydana gelen durumlar.

\begin{tabular}{|c|c|c|}
\hline \multirow{4}{*}{ 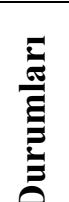 } & A1 & Öğrencilerin üzerindeki işaretçi cihazlar Bluetooth cihazları yayarlar \\
\hline & B1 & Mobil uygulama işaretçileri algılamak için belirli bir UUID kullanır \\
\hline & B2 & İşletim sistemi (Operating system, OS) taramayı başlatır \\
\hline & B3 & Alınan işaretçi cihaz paketleri (UUID, majör ve minör bilgileri) \\
\hline e & B4 & OS işaretçi cihazları algılar \\
\hline$\overline{0}$ & B5 & OS uygulamaya aldığı cihazları bildirir \\
\hline$\stackrel{\mathbf{Y}}{\mathbf{S}}$ & B6 & Mobil uygulama arka planda çalışmaya başlar ve kendi servisindeki öğrencileri tespit eder \\
\hline 可 & B7 & Alınan öğrenci adı ve soyadı bilgileri \\
\hline 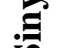 & $\mathbf{B 8}$ & Mobil uygulama öğrencileri sürücüyü bilgilendirmek için listeler. \\
\hline & B9 & Mobil uygulama hücresel veri ile belirli aralıklarla Firebase veri tabanına konum bilgisini iletir \\
\hline
\end{tabular}




\begin{tabular}{l|l|l}
\hline C1 & Oturum açma isteği (Okul numarası ve parola) \\
\hline C2 & Öğrenci bilgileri (Araç ID, UUID, majör, minör, tarih, saat) \\
\hline C3 & Firebase veri tabanında öğrencilerin durum bilgisi “true" olarak değiştirilir \\
\hline C4 & Alınan konum bilgisi (enlem ve boylam ) \\
\hline C5 & Firebase veri tabanında servisin konum bilgisi gelen veriler doğrultusunda güncellenir \\
\hline D1 & Alınan oturum açma isteği kabul edildi bilgisi \\
\hline D2 & Alınan öğrenci bilgileri (servise biniş saati, servisten iniş saati, servisten hangi konumda indiği) \\
\hline D3 & OS gelen bilgileri uygulamaya bildirir \\
\hline D4 & Mobil uygulama öğrenci bilgilerini ara yüzde görüntüler \\
\hline D5 & Alınan araç ID konum bilgisi \\
\hline D6 & Mobil uygulama konumu harita üzerinde görüntüler \\
\hline E1 & Uygulama sisteme yeni öğrenci ekler, siler ve günceller \\
\hline E2 & OS taramayı başlatır \\
\hline E3 & OS uygulamayı bilgilendirir \\
\hline E4 & Öğrenciler işaretçi cihaz UUID’leri ile eşleştirilirler \\
\hline E5 & Uygulama bütün öğrencileri ve kayıtlı oldukları servisleri görüntüler \\
\hline E6 & Uygulama OS tarafindan bekleme durumuna alınır \\
\hline E7 & Uygulama arka planda çalışır \\
\hline
\end{tabular}

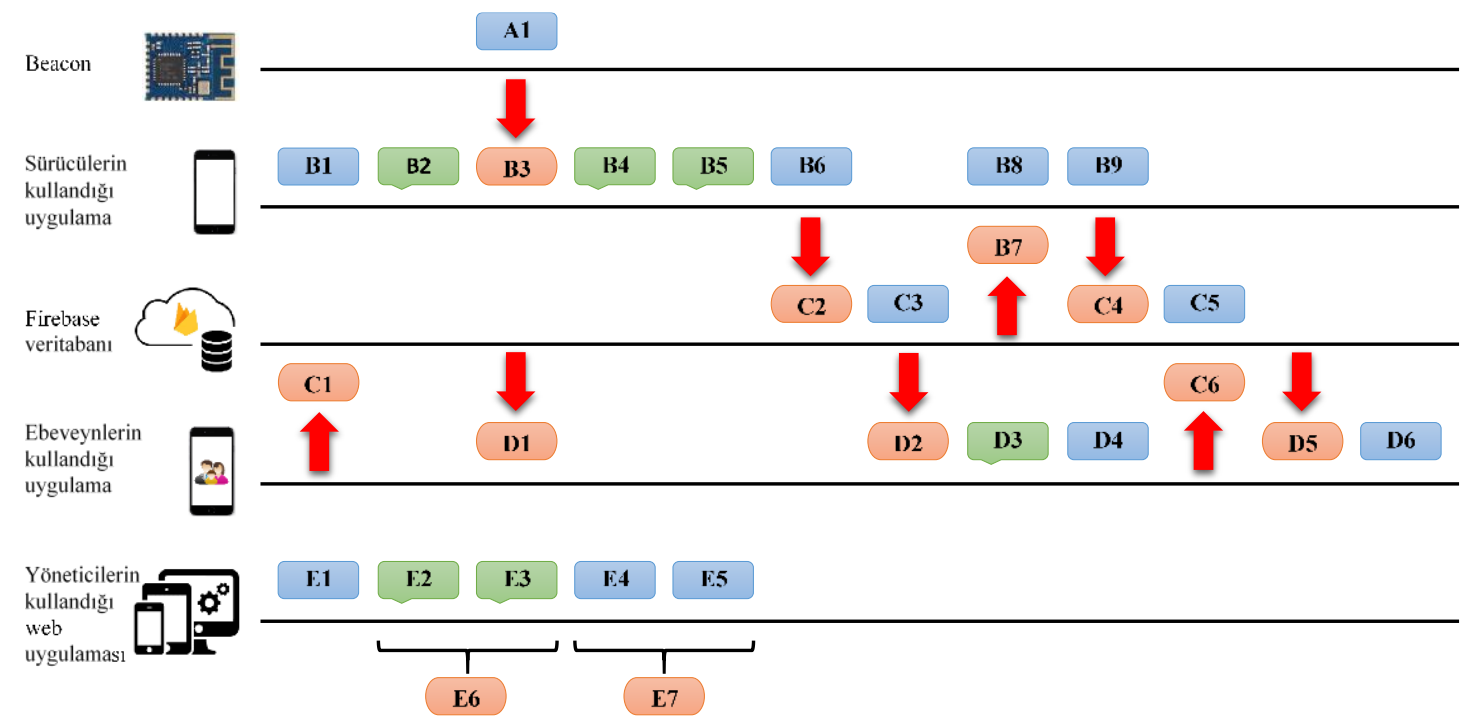

Şekil 4. Sistemin çalışma prensibi ve sinyalizasyon süreci.

\section{B. MOBILL UYGULAMA}

BLE işaretçi temelli Gerçek zamanlı okul servisi ve öğrenci takip sisteminin mobil uygulamaları blok programlamaya dayalı mobil uygulama geliştirme aracı olan MIT App Inventor ile gerçekleştirilmiştir. Geliştirilen sürücü uygulaması öğrencinin çantasında veya üzerinde bulundurduğu işaretçi cihazın sürücünün Bluetooth alıcısının kapsama alanına girdiğinde, işaretçi cihazın konumunu alarak hem uygulama ekranında belirli aralıklar güncellenerek göstermesini hem de güncel öğrenci listesinin saat, tarih ve konum bilgileri ile birlikte Firebase bulut platformundaki gerçek zamanlı veri tabanına yazmaktadır. Servis rutininin bitmesi ve öğrencilerin tamamının servisten inip inmediği kontrolü sürücü tarafından tamamen otomatik olarak uygulama üzerinden gerçekleştirilebilmektedir. Geliştirilen ebeveyn uygulaması ile kayıtlı ebeveyn öğrencisinin taşıdığı işaretçi cihazı gerçek zamanlı olarak görüntüleyebilmesinin dişında öğrencisinin servise bindiği ve servisten indiği durumlarda otomatik bildirim alabilmektedir. Böylelikle hem ebeveyn hem de sürücünün servis aracında öğrenci kalıp 
kalmadığı ile ilgili çift yönlü kontrol sağlanmış olmaktadır. MIT App Inventor kullanılarak geliştirilen uygulamalardan ebeveyn uygulamasının giriş ekranından sonra ilgili öğrenciye ait bilgilerin mobil uygulamada gösterilmesi için oluşturulan kod parçacığı bölümü Şekil 5'te gösterilmektedir. Şekil 6'da tasarlanan gerçek zamanlı okul servisi ve öğrenci takip sisteminin mobil uygulamalarının kullanıcı arayı̈ örnekleri gösterilmektedir.

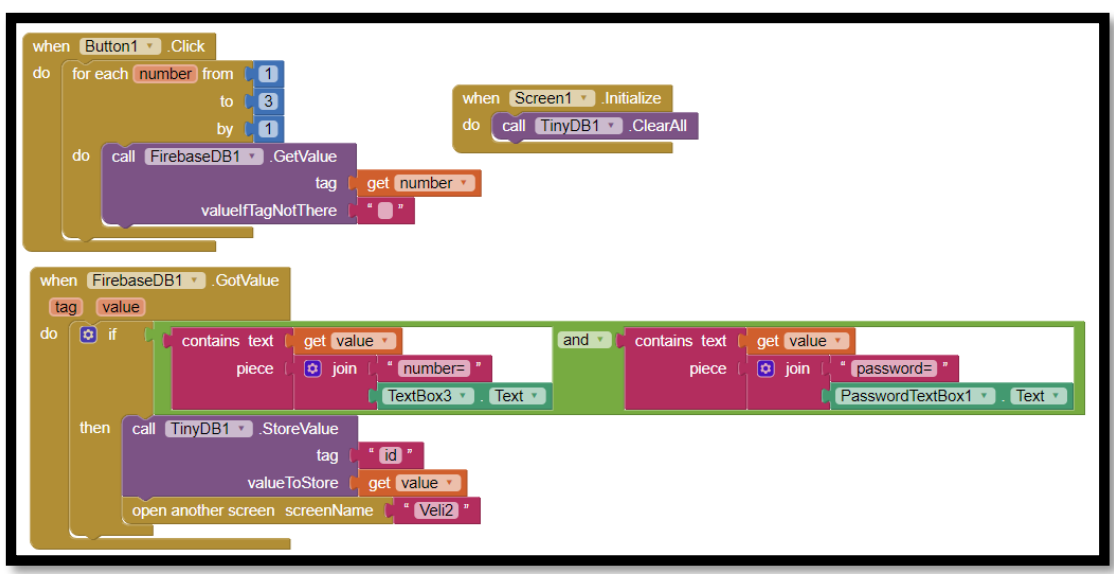

Şekil 5. Gerçek zamanlı okul servisi ve öğrenci takip sisteminin ebeveyn uygulamasl öğrenci bilgilerinin bulut platformdan ekrana basılması ile ilgili MIT App Inventor kod parçacıklarının gösterimi.
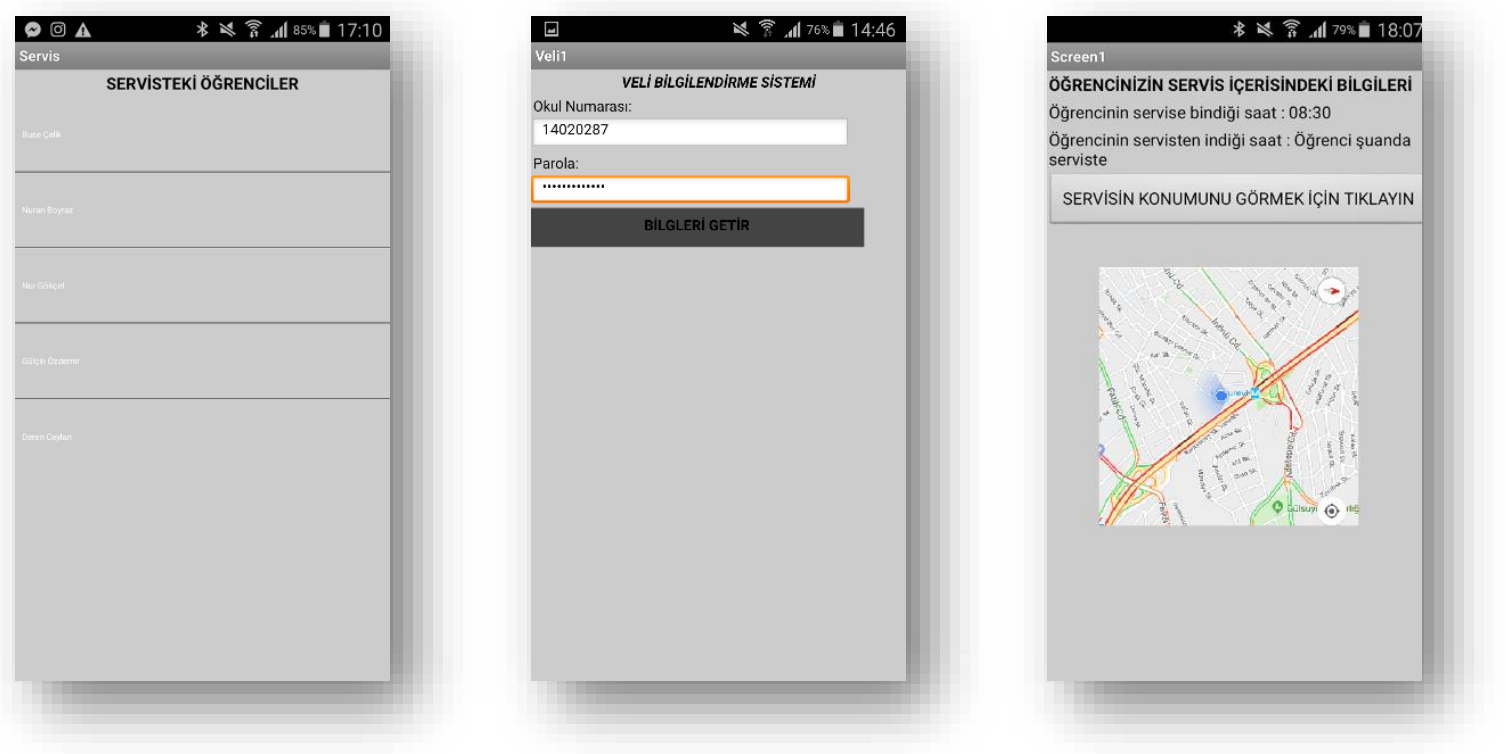

Şekil 6. Gerçek zamanlı okul servisi ve öğrenci takip sisteminin mobil uygulama ara yüzleri.

Ebeveynler giriş yaptıktan sonra gelen ekranda öğrencilerinin o anda serviste olup olmadıklarını, servise bindikleri saati, eğer servisten inmişler ise servisten indikleri saati ve servisin anlık olarak konumunu görüntüleyebilmektedirler.

\section{GERÇEK ZAMANLI OKUL SERVISİ VE ÖĞRENCİ TAKIP SISTEMİ YAZILIMI}

Web temelli gerçek zamanlı okul servisi ve öğrenci takip sistemi yazılımı, kullanıcının öğrenci ekleyebilmesini, gerektiğinde öğrenci bilgilerini düzenleyebilmesini, öğrencilerin ve servislerin bulut veri tabanında ilişkilendirilmesini sağlamaktadır. $\mathrm{Bu}$ yazılımın geliştirilmesinde HTML, CSS ve 
JavaScript teknolojilerinden faydalanılmıştır. Sistem yöneticileri gerçek zamanlı okul servisi ve öğrenci takip sistemi yazılımına Şekil 7'de verilen kullanıcı ara yüzünü kullanarak gerekli sistem giriş bilgileri ile yapabilmektedirler.

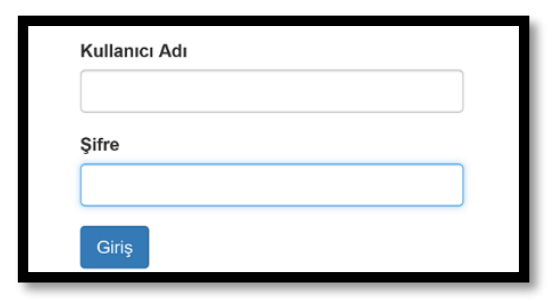

Şekil 7. Gerçek zamanlı okul servisi ve öğrenci takip sistemi yazılımı giriş ekranı.

Servis yazılımı yöneticisi gerçek zamanlı okul servisi ve öğrenci takip sistemi yazılımına giriş yaptığında öğrencilerin servis aracı, kullandıkları işaretçi cihazın UUID bilgisi, adı, soyadı ve kimlik bilgilerini görüntüleyebilmektedir (Şekil 8). Gerektiğinde bu bilgilerin güncellemesini yapabilmektedir. Bununla birlikte Beacon UUID, TC kimlik numarası, adı, soyadı ve öğrencinin kayıtlı olduğu servis plakasını girerek öğrenci ekleyebilmektedir. Eklenen, sistemdeki kayıtlı öğrencileri görüntülemesi ve gerektiğinde detay kısmına girip öğrenci bilgilerini düzenleyebilmesi (Şekil 9) veya öğrenciyi sistemden silebilmesi gibi özellikleri bulunmaktadır.

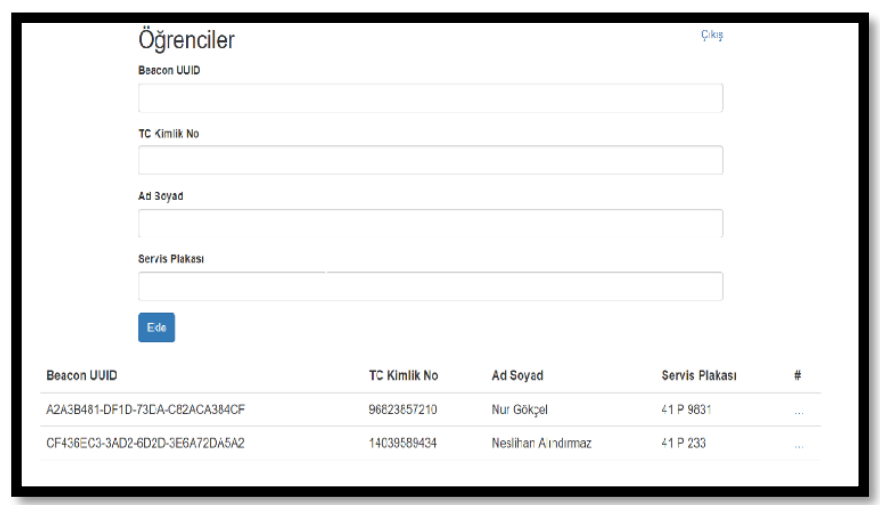

Şekil 8. Web temelli gerçek zamanlı okul servisi ve ögrenci takip sistemi yönetici ara yüzü.

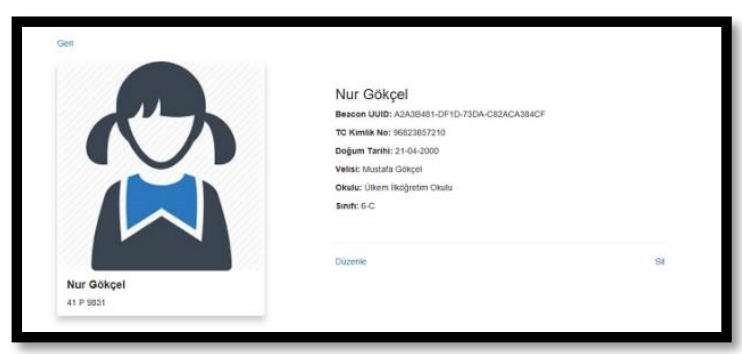

Şekil 9. Web temelli gerçek zamanlı okul servisi ve ögrenci takip sistemi Öğrenci detay ara yüzü.

\section{VERI TABANI MODELI}

$\mathrm{Bu}$ sistemde veri tabanı olarak Firebase kullanılmıştır. Firebase, JavaScript nesne gösterimi formatındaki (JavaScript Object Notation, JSON) verilerin uzak bir sunucuda gerçek zamanlı olarak 
depolanabildiği, ücretsiz kullanım sunan bulut platformdur. Günümüzde uygulamalar platform fark etmeksizin aynı veriye her cihazdan erişmek istemektedir. Gerçek zamanlı okul servisi ve öğrenci takip sistemi farklı iki mobil uygulama ve bir web uygulaması şeklinde tasarlanmıştır. Şekil 10' da geliştirilen okul servisi ve öğrenci takip sistemi sisteminin Firebase gerçek zamanlı veri tabanı modeli sunulmaktadır. Bu sistemde gerektiğinde tüm kullanıcılar farklı yerlerden aynı veriye Firebase'in ilişkisel bulut veri tabanı hizmeti sayesinde WebSocket yapısı ile erişebilmektedir. Uygulama, yönetim, kullanım, takip, veri depolama, bildirim gönderme gibi işlemleri, ek bir sunucuya ve sunucu taraflı kod yazmaya gerek kalmadan çözen Firebase, yeni geliştirici dostu ara yüzünde gerçek zamanlı veri tabanı, bildirim, uzaktan yapılandırma gibi özelliklerle donatılmıştır [18-19]. Firebase'in gerçek zamanlı bir veri tabanı olması, sistemde servis konumunun anlık olarak takip edilebilmesini ve anlık bildirimler yapılabilmesini sağlamaktadır.

\section{$\underline{\text { V. SONUCLLAR }}$}

Günümüz mobil kullanıcılarının hemen hemen hepsinin Bluetooth düşük enerji modülü desteğine sahip olmaları nedeniyle Bluetooth 4.0 ve üzeri kablosuz iletişim teknolojisini kullanan işaretçilerin etkileşim bölgelerine girdiğinde birçok üretici ve geliştiriciler tarafından üretilen farklı içeriklere erişim imkânı sağlamaktadırlar. İşaretçi cihazlar (Beacon) alı̧̧-veriş, kişi takibi, gömülü sistem entegrasyonu, çevre sorunlarının izlenmesi ve bina içi yönlendirme, stok takibi gibi çok geniş uygulama alanında kullanımını beraberinde getirmektedir. Bu çalışmada, birçok alanda kullanılmaya başlanan nesnelerin interneti teknolojisinin alt bileşenlerinden olan işaretçi cihazların kullanımına dayalı öğrenci ve servis takibi üzerine bir sistem tasarımı üzerinde durulmuştur. Geliştirilen sistem öğrencilerin servislerine bindiğinde TI CC2541 çipini içeren HM-11 işaretçi cihaz ile iletişime geçerek bulunduğu konum ve süreyi de göz önüne alarak kullanıcı hareketlerini anlık olarak takip edilebilmesini sağlamaktadır. Bunun için MIT App Inventor kullanılarak işaretçi cihazlar ile servis kapsama alanı içerisinde iletişim kurabilen mobil uygulamalar geliştirilmiştir. Mobil uygulamanın hücresel veri iletişimini kullanarak Firebase veri tabanını kullanmasıyla birlikte sistem gerçek zamanlı bilgilendirmeler sunabilmektedir. Böylelikle öğrencinin servise olup olmadığ 1 , servise ne zaman bindiği hangi saate servisten indiği izlenebilmektedir. Bununla birlikte sistem servisteki tüm öğrencilerin inip inmediğinin kontrolünü de sağlamaktadır. Geliştirilen okul servisi ve öğrenci takip sistemi yapılacak küçük entegrasyon ve ürün süreçleri ile müze, ören yeri, kapalı alan takipleri gibi birçok süreçte de kullanılabilecektir. Böylelikle farklı gruplar için farklı raporlama imkânları sunulabilecektir. 


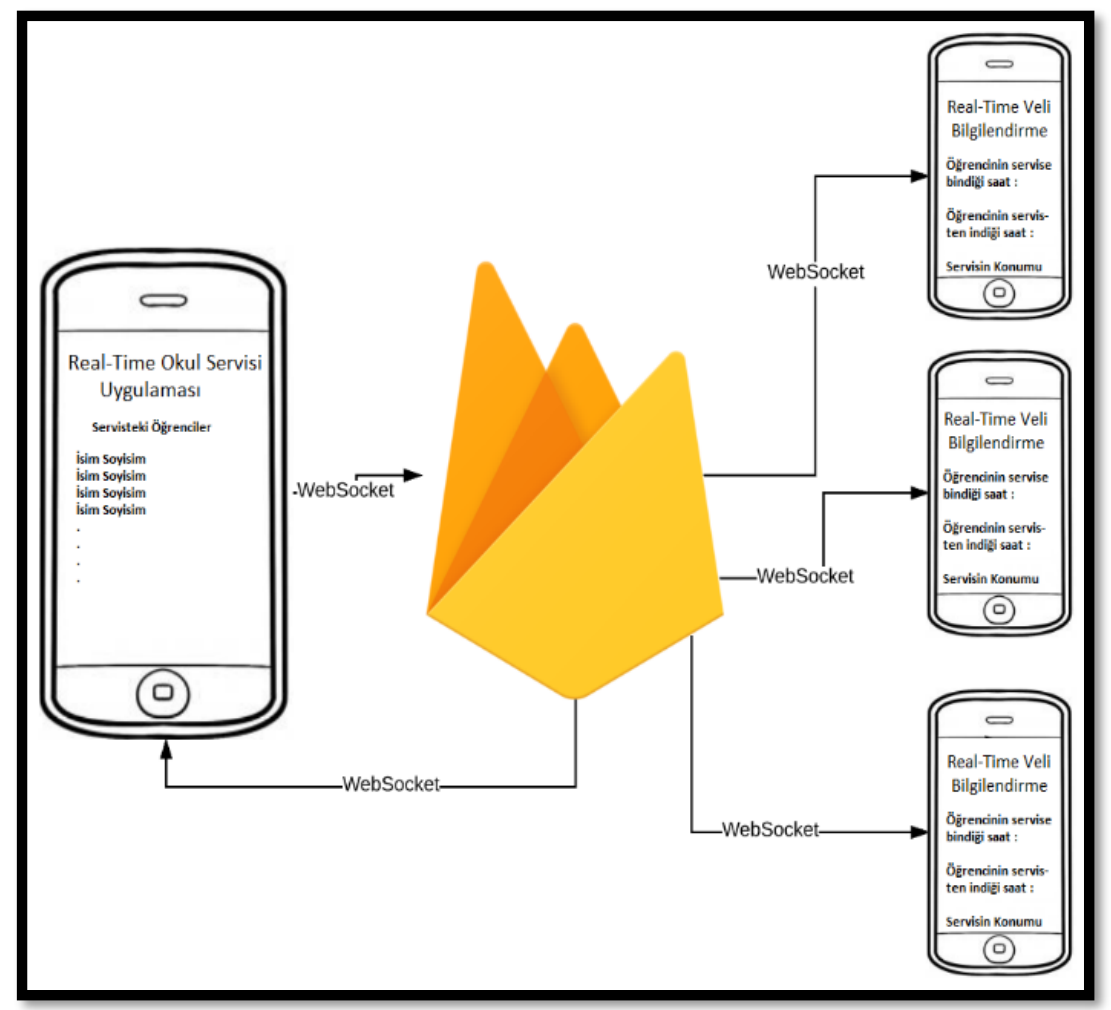

Şekil 10. Firebase yapısı

\section{KAYNAKLAR}

[1] Y. F. Bao, "Analysis of the learning evaluation of distance education based on the Internet of Things”, World Tran. on Engineering and Technology Education, vol. 14, no. 1, pp. 168-172, 2016.

[2] T. M. NG, 'From 'Where I Am' to 'Here I Am': accuracy study on location-based services with IBeacon technology," HKIE Transactions, vol. 22, no.1, pp. 23-31, 2015.

[3] F. Dalkılıç, U. C. Çabuk, E. Arıkan, ve A. Gürkan, "An analysis of the positioning accuracy of iBeacon technology in indoor environments," International Conference on Computer Science and Engineering, Antalya, Türkiye, 2017, pp. 549-553.

[4] F. Alam, R. Mehmood, I. Katib, N. N. Albogami, A. Albeshri, "Data Fusion and IoT for Smart Ubiquitous Environments: A Survey,” IEEE Access, vol. 5, pp. 9533-9554, 2017.

[5] S. Verma, Y. Kawamoto, Z. M. Fadlullah, H. Nishiyama, N. Kato, "A Survey on Network Methodologies for Real-Time Analytics of Massive IoT Data and Open Research Issues," IEEE Communications Surveys \& Tutorials, vol. 19, no. 3, pp. 1457-1477, 2017.

[6] O. B. Sezer, E. Dogdu, A. M. Ozbayoglu, "Context-Aware Computing, Learning, and Big Data in Internet of Things: A Survey,” IEEE Internet of Things Journal, vol. 5, no. 1, pp. 1-27, 2018. 
[7] H. Hoshi, H. Ishizuka, A. Kobayashi and A. Minamikawa, "An indoor location estimation using BLE beacons considering movable obstructions," Tenth International Conference on Mobile Computing and Ubiquitous Network, Toyama, Japan, 2017, pp. 1-2.

[8] C. Bayılmış, M. Özdemir, "Bluetooth Düşük Enerji Teknolojisine Sahip İşaretçi ve Akı1lı Telefon Temelli Öğrenci Yoklama Sistemi," Bilişim Teknolojileri Dergisi, vol. 9,no. 3, pp. 249-254, 2016.

[9] N. Stein, S. Urbanski, "Beacon Technology with IoT and Big Data", Internet of Things and Data Analytics Handbook, Wiley Telecom, 2017, ch. 16, pp. 267-280.

[10] Blesh, (2018, 22 May). Blesh Beacon Platform. Blesh Beacon Platform Access: https://www.blesh.com.

[11] R. C. Jisha, A. Jyothindranath, L. S. Kumary, "IoT based school bus tracking and arrival time prediction," International Conference on Advances in Computing, Communications and Informatics, Udupi, India, 2017, ss. 509-514.

[12] S. Shah, B. Singh, "RFID based school bus tracking and security system," International Conference on Communication and Signal Processing, Melmaruvathur, India, 2016, pp. 1481-1485.

[13] M. Ghareeb, A. Ghamlous, H. Hamdan, A. Bazzi, S. Abdul-Nabi, "Smart bus: A tracking system for school buses," Sensors Networks Smart and Emerging Technologies, Beirut, Lebanon, 2017, ss.1-3.

[14] J. T. Raj, J. Sankar, "IoT based smart school bus monitoring and notification system," IEEE Region 10 Humanitarian Technology Conference, Dhaka, Bangladesh, 2017, pp. 89-92.

[15] İSBAK, (2018, 22 Mayıs). Akıllı Ulaşım Çözümleri. İSBAK. Erişim: http://isbak.istanbul/akilliulasim-cozumleri/.

[16] K. E. Jeon, J. She, P. Soonsawad P. C. NG, "BLE Beacons for Internet of Things Applications: Survey, Challenges, and Opportunities," IEEE Internet of Things Journal, vol. 5, no. 2, pp. 811-828, 2018.

[17] G. Shan, B. H. Roh, "Advertisement Interval to Minimize Discovery Time of Whole BLE Advertisers," IEEE Access, vol. 6, pp. 17817-17825, 2018.

[18] W. J. Li, C. Yen, Y. S. Lin, S. C. Tung, S. Huang, "JustloT Internet of Things based on the Firebase real-time database," IEEE International Conference on Smart Manufacturing, Industrial \& Logistics Engineering, Hsinchu, Taiwan, 2018, pp. 43-47.

[19] A. Shukla, D. Hedaoo, M. B. Chandak, V. Prakashe, A. Raipurkar, "A novel approach: Cloudbased real-time electronic notice board," International Conference On Smart Technologies For Smart Nation, Bengaluru, India, 2017, pp. 1416-1423. 